\title{
Variabilidade genética de isolados de Beauveria spp. e virulência ao cascudinho Alphitobius diaperinus Panzer (Coleoptera: Tenebrionidae)
}

\section{Genetic variability of the fungus Beauveria spp. isolates and virulence to the lesser mealworm Alphitobius diaperinus Panzer (Coleoptera: Tenebrionidae)}

\author{
Daian Guilherme Pinto de Oliveira ${ }^{1 *}$; Fabiana Gisele da Silva Pinto ${ }^{2}$; \\ Fernando Gomes Barcellos 3 ; Luis Francisco Angeli Alves ${ }^{4}$; Mariangela Hungria ${ }^{5}$
}

\section{Resumo}

\begin{abstract}
A variabilidade genética de 13 isolados de Beauveria spp. foi avaliada por meio da técnica de RAPD, para verificar se há relação entre o perfil molecular e a origem geográfica dos isolados, hospedeiro inicial e virulência ao cascudinho dos aviários (Alphitobius diaperinus). Os bioensaios de virulência foram realizados com larvas e adultos do inseto, utilizaram-se os fungos na concentração de $10^{9}$ conídios $\mathrm{ml}^{-1} \mathrm{e}$ a mortalidade dos insetos foi avaliada durante dez dias. Com a técnica de RAPD foram testados 50 primers, dos quais sete apresentaram padrões de bandas consistentes. Pela análise dos perfis gerados observou-se a separação em dois grupos com nível de similaridade superior a $60 \%$, sendo que em um deles agruparam-se somente os isolados de cascudinho, com similaridade de $72 \%$. Verificouse relação entre o hospedeiro original dos isolados avaliados e o perfil molecular gerado nas análises. Não foi constatada qualquer relação entre os perfis moleculares e a região geográfica de procedência ou virulência ao inseto. Os resultados demonstraram que os isolados coletados em regiões próximas podem apresentar grande variabilidade genética.
\end{abstract}

Palavras-chave: Polimorfismo de DNA, controle microbiano, RAPD, fungos entomopatogênicos

\begin{abstract}
The genetic variability of 13 Beauveria spp. isolates was assessed by RAPD technique and verified the relationship between the molecular profiles generated and geographical location of isolates, the original host and pathogenicity to the lesser-mealworm Alphitobius diaperinus. Pathogenicity bioassays were carried with larvae and adult insects at fungal concentration of $10^{9}$ conidia / $\mathrm{mL}$, during a ten-day period. With RAPD technique, seven of 50 tested primers showed consistent banding patterns. Two groups with a similarity level above $60 \%$ were observed in the analysis profiles and one of them formed only by isolates from the lesser mealworm, with $72 \%$ of similarity. Was found relationship between the
\end{abstract}

${ }^{1}$ Prof. da Universidade Federal da Fronteira Sul, UFFS, Mestre em Entomologia pela Escola Superior de Agricultura 'Luiz de Queiroz', ESALQ. Doutorando em Entomologia pela Universidade Federal do Paraná, UFPR. E-mail: daian.oliveira@uffs.edu.br

${ }^{2} \mathrm{Dr}^{\mathrm{a}}$ em Microbiologia, UEL. Professora e pesquisadora na Universidade Estadual do Oeste do Paraná, UNIOESTE - Cascavel, PR, Centro de Ciências Biológicas e da Saúde. E-mail: fabianagsp@yahoo.com.br

3 Dr. em Agronomia, USP. Professor na Universidade Paranaense, Umuarama, PR. E-mail: fgbarcel@yahoo.com.br

${ }^{4}$ Dr. em Entomologia, ESALQ, Professor e pesquisador na Universidade Estadual do Oeste do Paraná, UNIOESTE - Cascavel, PR. Centro de Ciências Biológicas e da Saúde. E-mail: lfaalves@unioeste.br

5 Pós-Doutora Pesquisadora da Embrapa Soja, Londrina, PR. Laboratório de Biotecnologia dos Solos. E-mail: hungria@cnpso. embrapa.br

* Autor para correspondência 
origin host of the isolates and the molecular profile, generated in the analysis. There was no relationship between the molecular profiles and the geographical location or pathogenicity to the insect. The results showed that even the isolates collected in near areas may have highly variability.

Key words: DNA polymorphism, microbial control, RAPD, entomopathogenic fungi

\section{Introdução}

O cascudinho, Alphitobius diaperinus Panzer (Coleoptera: Tenebrionidae), coloniza o substrato das granjas avícolas, e é considerado praga por causar problemas sanitários e econômicos. Afeta a saúde e o crescimento das aves e atua como transmissor de parasitas, vírus e bactéria patogênicos às aves, além de causar danos estruturais aos aviários (CHERNAKI-LEFFER et al., 2001).

Métodos alternativos têm sido pesquisados com o objetivo de reduzir a utilização de inseticidas químicos, e o controle microbiano se destaca como uma opção viável de controle desta praga (CRAWFORD; BROOKS; ARENDS, 1998). Além de já ter sido verificada a ocorrência natural dos fungos entomopatogênicos Beauveria bassiana (Bals.) Vuill. e Metarhizium anisopliae (Metsch.) Sorok. em aviários (STEINKRAUS; GEDEN; RUTZ, 1991; ALVES et al., 2004; 2005), estudos de controle biológico realizados com estes patógenos apresentaram resultados satisfatórios na mortalidade de larvas e adultos do cascudinho em condições de laboratório (CRAWFORD; BROOKS; ARENDS, 1998; GEDEN et al., 1998; CHERNAKI-LEFFER et al., 2001; ROHDE et al., 2006; GINDIN et al., 2009).

Para seleção e introdução destes fungos no controle microbiano de insetos, deve-se considerar a variabilidade genética natural entre populações e isolados. Neste sentido, a técnica de RAPD (Random Amplified Polymorphic DNA) (WELSH; MCCLELLAND, 1990; WILLIAMS et al., 1990) têm sido extensivamente utilizada para gerar fingerprints, que é aplicada com sucesso para caracterizações moleculares de fungos entomopatogênicos (BIDOCHKA et al., 1994; TIGANO-MILANI; GOMES;
SOBRAL, 1995; FUNGARO, 1996; HEGEDUS; KHACHATOURIANS, 1996; BERRETTA et al., 1998).

Inúmeros trabalhos com o fungo $B$. bassiana foram realizados adotando-se esta técnica, a fim de se estabelecer uma possível relação entre os padrões de banda de RAPD gerados e alguns fatores como hospedeiro inicial, virulência e origem geográfica (BRIDGE et al., 1997; MAURER, 1997; URTZ; RICE, 1997; BERRETTA et al., 1998; GLARE; INWOOD, 1998; GAITAN et al., 2002; DOLCI et al., 2006).

No Brasil, pouco foi realizado a fim de avaliar esta variabilidade de isolados associados ao cascudinho, existindo apenas o trabalho de Santoro et al. (2008). Desta forma, o objetivo deste estudo foi caracterizar, pela técnica de RAPD, isolados de B. bassiana e Beauveria sp., verificando se existe uma relação entre o perfil molecular gerado e a origem geográfica, hospedeiro inicial ou virulência dos isolados.

\section{Material e Métodos}

Virulência de Beauveria bassiana a larvas e adultos de Alphitobius diaperinus

Foram utilizados 13 isolados, sendo dois de Beauveria sp. (outgroups), da coleção do Laboratório de Entomologia da Embrapa Soja (isolados CNPSO-Bb70 e 71), os quais foram testados anteriormente por Chernaki-Leffer (2004) e não apresentaram mortalidade confirmada para o cascudinho. Os demais isolados de $B$. bassiana obtidos de diferentes hospedeiros e previamente testados quanto à patogenicidade ao cascudinho, foram provenientes da coleção da Universidade Estadual do Oeste do Paraná (Tabela 1). 
Os isolados foram multiplicados em placas de Petri com meio para produção de esporos (ME) (ALVES et al., 1998). Após o plaqueamento foram incubados em câmara climatizada $\left(26 \pm 2{ }^{\circ} \mathrm{C}\right.$ e $14 \mathrm{~h}$ de fotofase), por um período de sete a 10 dias para crescimento e conidiogênese. Após este período, os conídios foram coletados, raspando-se a superfície do meio de cultura, e armazenados em freezer (colocar a temperatura) para posterior utilização.

Tabela 1. Isolados de Beauveria spp. utilizados no estudo e respectiva mortalidade confirmada de Alphitobius diaperinus (Coleoptera, Tenebrionidae) inoculados com 1x109 conídios ml-1 após 10 dias de avaliação.

\begin{tabular}{|c|c|c|c|c|c|}
\hline \multirow{2}{*}{ Isolado } & \multirow{2}{*}{ Espécie } & \multirow{2}{*}{$\begin{array}{c}\text { Origem Geográfica } \\
\text { (PR) }\end{array}$} & \multirow{2}{*}{ Hospedeiro } & \multicolumn{2}{|c|}{ Mortalidade (\%) } \\
\hline & & & & Larvas & Adultos \\
\hline Unioeste-04 & B. bassiana & Cascavel & A. diaperinus & $92 \pm 6,3 \mathrm{~A}$ & $90 \pm 1,9 \mathrm{~A}$ \\
\hline Unioeste-42 & B. bassiana & Cascavel & Coleoptera, Erotylidae & $35 \pm 5,4 \mathrm{C}$ & $5 \pm 3,7 \mathrm{D}$ \\
\hline Unioeste-44 & B. bassiana & Toledo & Hemiptera, Pentatomidae & $73 \pm 4,7 \mathrm{AB}$ & $7 \pm 2,7 \mathrm{D}$ \\
\hline Unioeste-45 & B. bassiana & Mal. Cândido Rondon & Coleoptera, Chrysomelidae & $33 \pm 6,1 \mathrm{~B}$ & $5 \pm 3,2 \mathrm{D}$ \\
\hline Unioeste-49 & B. bassiana & Cascavel & A. diaperinus & $63 \pm 8,8 \mathrm{AB}$ & $43 \pm 6,4 \mathrm{BC}$ \\
\hline Unioeste-50 & B. bassiana & Boa Vista de Aparecida & A. diaperinus & $53 \pm 8,6 \mathrm{AB}$ & $28 \pm 3,2 \mathrm{CD}$ \\
\hline Unioeste-51 & B. bassiana & Boa Vista de Aparecida & A. diaperinus & $65 \pm 8,1 \mathrm{AB}$ & $25 \pm 3,2 \mathrm{CD}$ \\
\hline Unioeste-52 & B. bassiana & Boa Vista de Aparecida & A. diaperinus & $78 \pm 7,4 \mathrm{~A}$ & $38 \pm 3,2 \mathrm{C}$ \\
\hline Unioeste-53 & B. bassiana & Cascavel & A. diaperinus & $93 \pm 2,7 \mathrm{~A}$ & $70 \pm 7,9 \mathrm{AB}$ \\
\hline Unioeste-54 & B. bassiana & Cascavel & Hemiptera, Pentatomidae & $85 \pm 7,4 \mathrm{~A}$ & $70 \pm 9,3 \mathrm{AB}$ \\
\hline Unioeste-56 & B. bassiana & Cascavel & Coleoptera, Curculionidae & $85 \pm 6,9 \mathrm{~A}$ & $82 \pm 4,2 \mathrm{~A}$ \\
\hline Cnpso-Bb70 & Beauveria sp. & Mariópolis & Coleoptera, Chrysomelidae & $0 \pm 0,0$ & $0 \pm 0,0$ \\
\hline Cnpso-Bb71 & Beauveria sp. & Mariópolis & Coleoptera, Chrysomelidae & $0 \pm 0,0$ & $0 \pm 0,0$ \\
\hline
\end{tabular}

Médias ( \pm EPM) seguidas da mesma letra maiúscula na coluna, não diferem entre si segundo o teste de Tukey $(\mathrm{P}<0,05)$.

Nos bioensaios, realizados segundo método utilizado por Rohde et al. (2006), larvas com 1 $\mathrm{cm}$ de comprimento e adultos foram transferidos para recipientes plásticos descartáveis, onde foram imersos em $1 \mathrm{ml}$ (em cada repetição) de suspensão de conídios na concentração de $1 \times 10^{9}$ conídios/ $\mathrm{ml}$ (solução de Tween ${ }^{\circledR} 80-0,01 \%$ ), sendo agitados durante 10 segundos. Na testemunha, os insetos foram imersos somente na solução de Tween 80 .

Em seguida, as larvas foram individualizadas em caixas de acrílico para se evitar o canibalismo, e os adultos mantidos em placas de Petri, ambas com papel-filtro e ração para aves esterilizada, para a alimentação dos insetos. Utilizaram-se quatro repetições com 15 insetos para cada isolado, incubando-se sob condições controladas $\left(26 \pm 2{ }^{\circ} \mathrm{C}\right.$ e $14 \mathrm{~h}$ de fotofase), em recipientes plásticos fechados, contendo espuma umedecida no fundo. As avaliações foram realizadas diariamente, durante 10 dias. Os cadáveres foram desinfestados em álcool $70 \%$ por 5 segundos, lavados em água destilada, e transferidos individualmente para câmara úmida para permitir o desenvolvimento do fungo e confirmar o agente causal da morte.

\section{Produção dos fungos e extração de DNA}

Os isolados obtidos a partir de coleção monospórica foram multiplicados em placas de Petri contendo o meio para produção de esporos, e mantidos em câmara climatizada $\left(26 \pm 2^{\circ} \mathrm{C}\right.$ e fotófase de $14 \mathrm{~h}$ ) por 10 dias. Em seguida, os conídios foram suspensos em tubos com $10 \mathrm{ml}$ de solução de Tween $80(0,01 \%)$ e homogeneizados sob agitação por um minuto. Inoculou-se $1 \mathrm{ml} \mathrm{da}$ suspensão de conídios em frascos com $500 \mathrm{ml}$ de meio líquido batata-dextrose ( $2 \mathrm{~g}$ de infuso de batata e $10 \mathrm{~g}$ de dextrose), sendo incubados por 72 horas sob 
agitação de $110 \mathrm{rpm}$ a $26 \pm 2^{\circ} \mathrm{C}$. Após a incubação, o micélio foi separado em filtro Büchner, lavado com água destilada esterilizada e, em seguida, pesado e armazenado a $-80^{\circ} \mathrm{C}$ até o momento da extração.

Para a extração do DNA, segundo Raeder e Broda (1985), o micélio foi triturado em um cadinho contendo nitrogênio líquido e, em seguida, distribuído em tubos de microcentrífuga, onde foi acrescentado $1 \mathrm{ml}$ tampão de extração [200 mM Tris-HCl (pH 8,0), 0,5\% SDS, $250 \mathrm{mM} \mathrm{NaCl}, 50$ $\mathrm{mM}$ EDTA e $100 \mathrm{mg} / \mathrm{mL}$ proteinase $\mathrm{K}$ ], sendo a mistura incubada por 15 minutos a $65^{\circ} \mathrm{C}$. Em seguida, adicionou-se $0,5 \mathrm{ml}$ de fenol, misturouse as fases e centrifugou a amostra a $12.000 \mathrm{rpm}$ por 15 minutos, em microcentrífuga. Desprezou-se a fase fenólica e acrescentou-se à fase aquosa 0,5 $\mathrm{ml}$ da solução de clorofórmio comálcool isoamílico (24:1). As fases foram misturadas e a amostra foi centrifugada como no passo anterior.

A fase aquosa foi trasferida para outro tubo em que se adicionaram dois volumes $(1 \mathrm{ml})$ de etanol absoluto. As amostras foram mantidas por 2 horas a $-20^{\circ} \mathrm{C}$ e posteriormente, centrifugadas a 12.000 rpm por 15 minutos. O sobrenadante foi descartado e o precipitado de DNA foi lavado em $500 \mu \mathrm{L}$ de álcool $70 \%$. Após a secagem do DNA à temperatura ambiente, o DNA foi ressuspendido em $200 \mu \mathrm{L}$ de Tampão TE (Tris HCl 1M-EDTA 0,5M).

\section{Quantificação de DNA e RAPD}

A quantificação do DNA total de cada isolado foi estimada em espectrofotômetro (Spectronic Genesys 2 ${ }^{\mathrm{TM}}$, Thermo Fisher Scientific) e a sua qualidade foi verificada em gel de agarose $1 \%$ corado com brometo de etídeo $(10 \mathrm{mg} / \mathrm{ml})$, com o auxílio do marcador Low DNA Mass Ladder de origem comercial.

Foram testados 50 primers (Operon Technologies $\left.^{\circledR}\right)$, dos quais sete apresentaram padrões de bandas consistentes: OPA-02, 5'-TGCCGAGCTG; OPA-03, 5'-AGTCAGCCAC; OPB-10, 5'-CTGCTGGGAC; OPE-07, 5'-AGATGCAGCC; OPQ-01, 5'-GGGACGATGG; OPQ-04, 5'-AGTGCGCTGA e OPQ-05, 5'-CCGCGTCTTG.

As reações de amplificação foram preparadas para um volume final de $25 \mu \mathrm{L}$, contendo: $1 \mathrm{X}$ tampão (Tris $\mathrm{HCl} 200 \mathrm{mM} \mathrm{pH} \mathrm{8,4,} \mathrm{KCl} 500 \mathrm{mM}$ ); $2 \mathrm{mM} \mathrm{MgCl} 2,200 \mu \mathrm{M} \mathrm{dNTP}, 0,2 \mu \mathrm{M}$ de primer, $1 \mathrm{U}$ Taq DNA polimerase e 10-20 ng do DNA genômico. As reações foram realizadas em termociclador (MJ Research- PTC-200) programado para realizar uma desnaturação a $94^{\circ} \mathrm{C}$ por 5 minutos, seguida de 40 ciclos de 1 minuto a $92^{\circ} \mathrm{C}, 1$ minuto a $35^{\circ} \mathrm{C}, 2$ minutos a $72^{\circ} \mathrm{C}$ e uma extensão final de 5 minutos a $72^{\circ} \mathrm{C}$. Os produtos das amplificações foram separados por eletroforese em gel de agarose a $1,4 \%$, a $120 \mathrm{~V}$ por 7 horas. Utilizou-se como padrão de peso molecular o marcador $1 \mathrm{~Kb}$ plus DNA Ladder (Life Technologies ${ }^{\circledR}$ ) e os géis foram corados com brometo de etídeo a $10 \mathrm{mg} / \mathrm{mL}$ e fotografados com aparelho Kodak Digital Science 120. Os perfis obtidos foram confirmados em triplicata.

\section{Análise dos dados}

Os dados de mortalidade foram transformados em $\operatorname{arcsen} \sqrt{x / 100}$ para análise de variância (teste F) e as médias foram comparadas entre si pelo teste de Tukey $(\mathrm{P}<0,05)$, utilizando-se o programa estatístico SAS (SAS, 2003).

Os dados obtidos com as técnicas moleculares foram analisados com o uso do programa Bionumerics (Applied Mathematics, Kortrijk, Bélgica, versão 2.0); para o agrupamento foi usado o algoritmo UPGMA (Unweighted pair-group method with arithmetic mean) (SNEATH; SOKAL, 1973) e o coeficiente de Jaccard, em um nível de tolerância de 3\%. 


\section{Resultados e Discussão}

Virulência de Beauveria bassiana a larvas e adultos de Alphitobius diaperinus.

O resultado dos bioensaios demonstrou considerável diferença entre a virulência relativa a larvas e adultos de $A$. diaperinus. Todos os isolados de $B$. bassiana foram patogênicos ao cascudinho, com valores de mortalidade confirmada variando entre $33 \%$ e $93 \%$ para larvas $\left(F_{10,33}=10,7 ; \mathrm{P}<0,0001\right.$; $\mathrm{CV}=20,9 \%)$, e entre $5 \%$ e $90 \%$ para adultos $\left(F_{10,33}=\right.$ 28,$5 ; \mathrm{P}<0,0001 ; \mathrm{CV}=18,5 \%$ ) (Tabela 1). O isolado mais virulento foi Unioeste- 04 , com $92 \%$ e $90 \%$ de mortalidade para larvas e adultos, respectivamente, valores estes próximos aos observados por Rohde et al. (2006).
Caracterização de isolados de Beauveria bassiana por RAPD

Observaram-se, nos isolados Unioeste-04, Unioeste-50 e Unioeste-51 dois padrões de bandas, um representando o próprio DNA genômico, e outro representando provavelmente dsRNA (RNA de dupla fita) (Figura 1). Estas bandas extras têm sido descritas na literatura para várias espécies de fungos como sendo de origem viral, porém, a sua influência na ação do fungo não é muito conhecida (HUNST; LATTERELL; ROSSI, 1986), sendo possível que estejam relacionadas à virulência dos isolados. Em estudos realizados por Martins et al. (1999) com o fungo $M$. flavoviride, não foi observado a influência da presença de dsRNA em nenhuma das variáveis analisadas. Porém, testes feitos por Dalzoto et al. (2006) comprovaram redução na produção de conídios e virulência em isolados de B. bassiana que apresentaram dsRNA. Assim, novos estudos são necessários para compreender melhor esta questão.

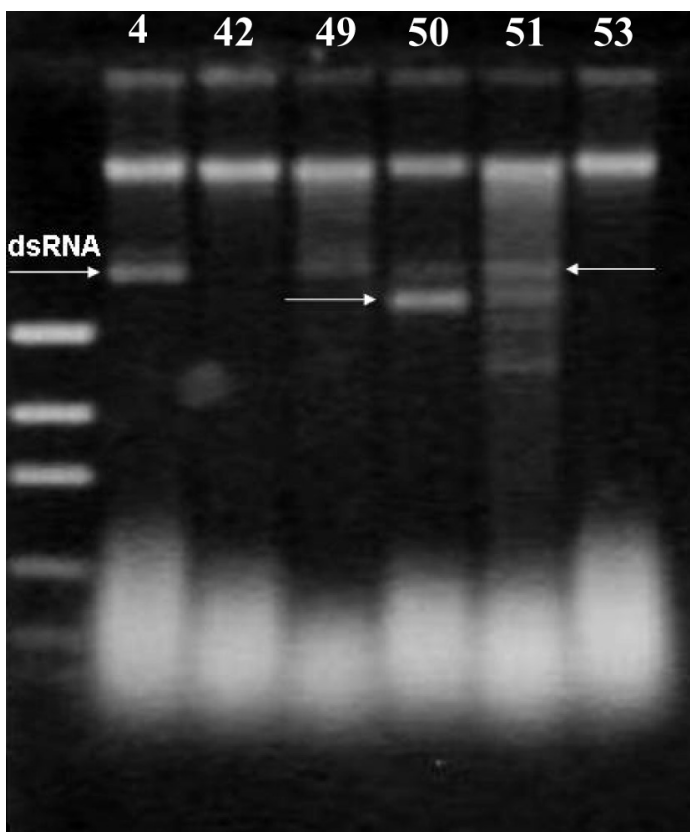

Figura 1. DNA genômico dos isolados de Beauveria bassiana Unioeste-04, Unioeste-42, Unioeste-49, Unioeste-50, Unioeste-51, Unioeste-53 respectivamente, com presença de bandas extras indicadas pelas setas nos isolados Unioeste-04, Unioeste-50 e Unioeste-51. 
Por meio de sete marcadores RAPD utilizados para analisar os 13 isolados de Beauveria sp. e $B$. bassiana, foram geradas bandas com tamanhos que variaram entre 150 bp e 2900 bp. O número mínimo e máximo de bandas observadas foi de 13 (marcador OPQ-05) e 23 (marcador OPB-10), respectivamente, sendo que a maioria dos loci apresentaram-se polimórficos (Figura 2, A e B). Estes resultados corroboram outros estudos com RAPD em $B$. bassiana, em que foi constatado um grau elevado de polimorfismo entre os isolados avaliados (URTZ; RICE, 1997; MAURER et al., 1997; CASTRILLO; BROOKS, 1998; CASTRILLO; WIEGMANN; BROOKS, 1999).

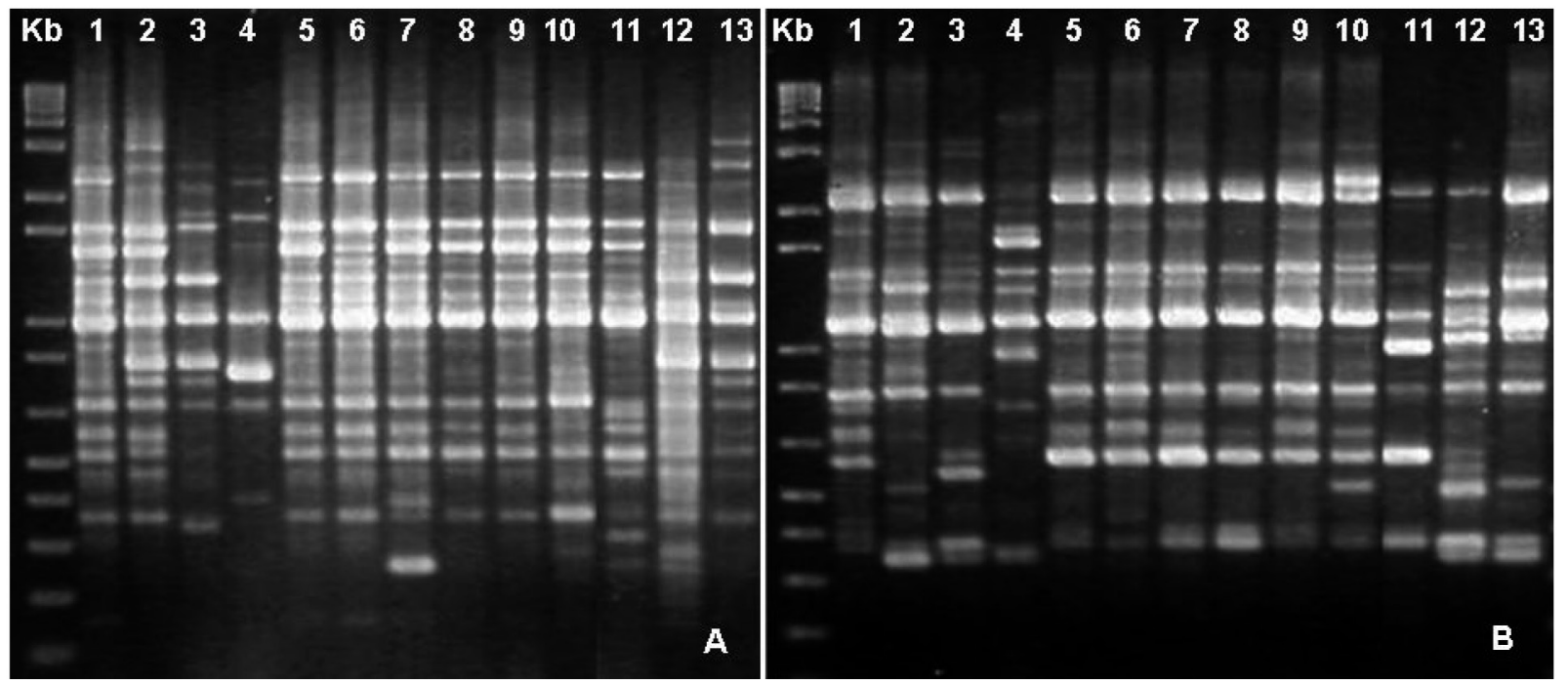

Figura 2. Perfis de RAPD dos isolados de Beauveria spp. (1-Unioeste-04, 2-Unioeste-42, 3-Unioeste-44, 4-Unioeste-45, 5-Unioeste-49, 6-Unioeste-50, 7-Unioeste-51，8-Unioeste-52，9-Unioeste-53，10-Unioeste-54, 11-Unioeste-56, 12-CNPSo-Bb70 e 13-CNPSo-Bb71) amplificados em (A) com o primer OPB-10 e em (B) com OPQ-01; o Kb representa o marcador utilizado.

A análise dos padrões de bandas de $B$. bassiana permitiu o agrupamento dos isolados em dois grupos com nível de similaridade superior a $60 \%$, e mais três isolados que ocuparam posições isoladas, com destaque para o grupo II, no qual se agruparam todos os isolados de cascudinho, com similaridade de $72 \%$ (Figura 3). No grupo I, com $63 \%$ de similaridade, foram posicionados os isolados CNPSo-70 e 71 e, também, os isolados Unioeste-42 e 44, que são provenientes de diferentes origens geográficas e hospedeiros iniciais, compartilhando apenas a baixa virulência aos adultos de $A$. diaperinus, 5\% e 7\% para os dois últimos, respectivamente. $\mathrm{O}$ isolado que apresentou menor similaridade com os demais (47\%) foi o Unioeste-45. 


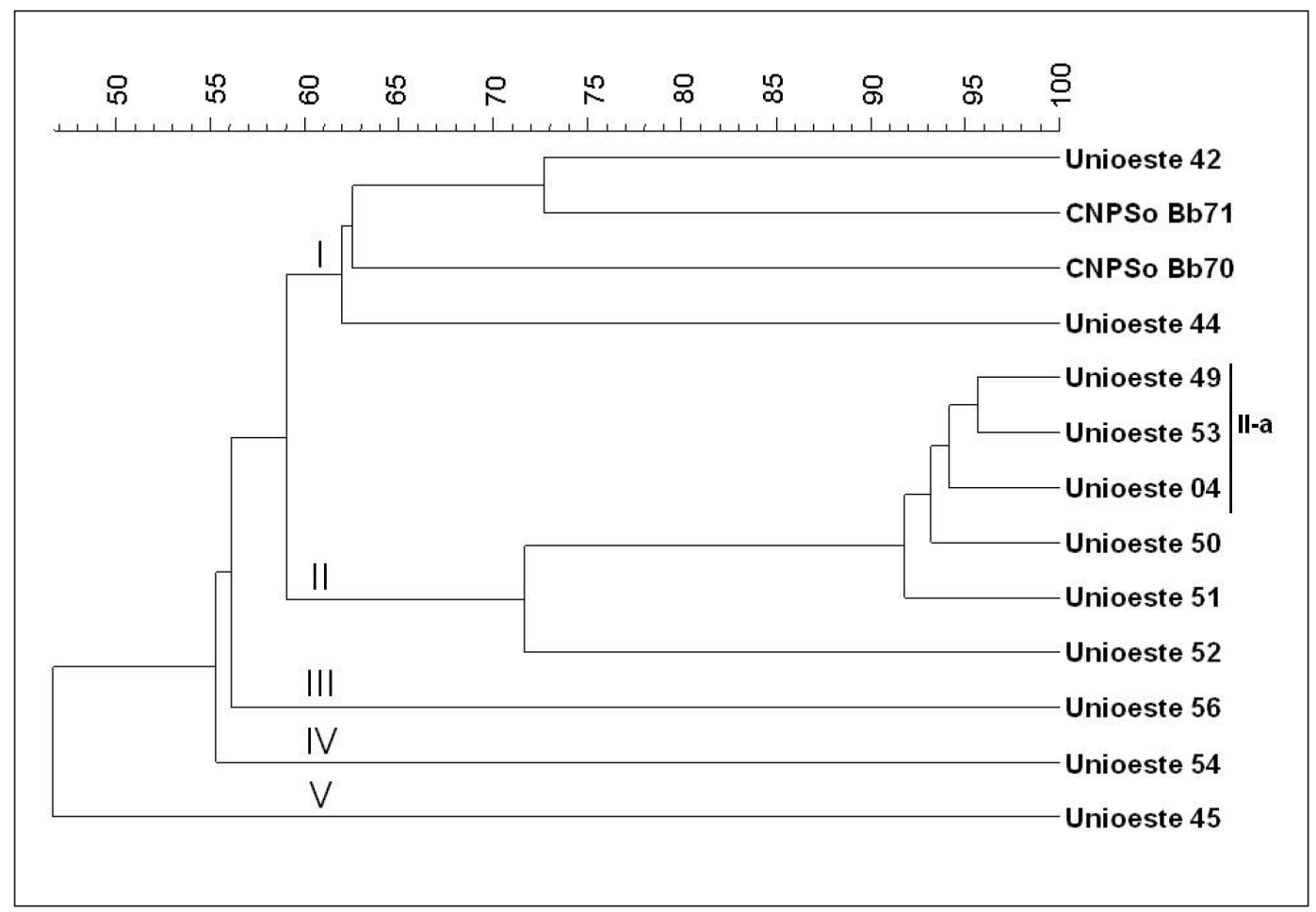

Figura 3. Dendrograma construído por agrupamento UPGMA, índice de Jaccard a 3\% de tolerância. Beauveria bassiana isolados de Alphitobius diaperinus pertencentes ao grupo II; isolados de outros hospedeiros pertencentes aos demais grupos; Subgrupo II-a: isolados a partir de A. diaperinus coletados em uma mesma cidade (Cascavel, PR).

Estes dados sugerem que existe uma associação entre os grupos gerados por RAPD e o hospedeiro inicial dos isolados testados, somente em relação ao cascudinho. Os resultados corroboram os obtidos por Maurer et al. (1997), que avaliaram, por meio da técnica de RAPD, 38 linhagens de B. bassiana, isoladas de diversos hospedeiros e diferentes regiões geográficas, e puderam concluir que o inseto hospedeiro parece ser o fator mais importante na estrutura da população deste entomopatógeno. Provavelmente isto se deve à íntima relação patógeno-hospedeiro, na qual existem muitos fatores que podem influenciar todo o processo de infecção e a dinâmica da doença.

Constatou-se também, que os isolados Unioeste-42 (B. bassiana) e CNPSo-71 (Beauveria sp.) que são de regiões diferentes, são muito similares entre si (73\%). Resultados semelhantes foram obtidos por Glare e Inwood (1998), quando avaliaram espécies de Beauveria procedentes da
Nova Zelândia com isolados de outros países, e puderam observar que isolados de diferentes regiões e espécies podem ser reunidos em um mesmo grupo de RAPD. No entanto, deve-se revisar a identificação taxonômica do isolado CNPSo-71, o qual não apresenta espécie definida. A relação de similaridade relativa entre estes isolados pode indicar que sejam de uma mesma espécie.

Em relação à origem geográfica dos isolados, no grupo II é possível verificar um subgrupo (IIa) com 94\% de similaridade (Figura 3), no qual estão os isolados de cascudinho coletados em uma mesma cidade, Cascavel, PR. É possível, porém, que esta relação não esteja ligada apenas à origem, visto que para os demais isolados não ocorreu qualquer relação entre o local de coleta e os grupos de RAPD. Os resultados contrapõem aqueles obtidos por Castrillo, Wiegmann e Brooks (1999) na avaliação da variabilidade genética de isolados de $B$. bassiana associados a $A$. diaperinus quando verificaram 
relação direta entre o local de coleta dos isolados e o perfil molecular gerado pelas bandas de RAPD. É provável que o maior número de isolados testados pelos autores no trabalho citado forneçam melhores subsídios para verificar tal relação e, além disso, os isolados avaliados no presente trabalho têm sua origem em um mesmo Estado, prejudicando uma inferência mais ampla.

Quanto à virulência, não foi possível estabelecer uma relação entre o agrupamento e o perfil molecular gerado, tanto para larvas quanto para adultos. Para larvas, os resultados de mortalidade de vários isolados foram estatisticamente semelhantes, $\mathrm{o}$ que não possibilita se estabelecer qualquer relação. Para os adultos, após a construção do dendrograma (Figura 3) os isolados Unioeste-04, 53, 54 e 56, os quais foram estatisticamente os mais virulentos, figuraram em grupos distintos, sendo sua relação provavelmente ligada somente ao hospedeiro inicial. Luz et al. (1998) e Devi et al. (2001) também não encontraram em seus estudos, relação entre os perfis de RAPD gerados e a virulência dos isolados de $B$. bassiana testados para e Chilo partellus Swinhoe (Lepidóptera: Pyralidae) e Triatoma infestans Klug (Hemiptera: Reduvidae), respectivamente.

De maneira diferente, Santoro et al. (2008) observaram em estudo utilizando RAPD, a distinção de um subgrupo contendo somente os isolados de $B$. bassiana virulentos para $A$. diaperinus, em contraposição aos demais grupos contendo apenas isolados não virulentos. Ainda no mesmo trabalho, os autores não obtiveram nenhuma relação entre os hospedeiros iniciais ou a origem dos isolados e os perfis moleculares gerados.

Tais divergências podem ser explicadas pelo elevado grau de variabilidade genética exibida pelos fungos entomopatogênicos, pois mesmo dentro de uma determinada população, o nível de polimorfismo entre os isolados pode ser altamente variável (SOSA-GÓMEZ; TIGANO; ARANTES, 1998; FERNANDES et al., 2006). Além disso, os isolados utilizados no referido trabalho não foram os mesmos utilizados no presente estudo. Segundo Castrillo e Brooks (1998), a variação genética está fortemente presente entre isolados de $B$. bassiana, e aspectos como reprodução, estratégias de sobrevivência, diversidade de hospedeiros e mecanismo de dispersão são fatores capazes de interferir na estrutura genética da população de um agente entomopatogênico, promovendo estas variações, como foi observado neste estudo.

Em relação a importância das caracterizações moleculares de isolados, Sosa-Gómez, Tigano e Arantes (1998) relatam que, antes de qualquer estudo sobre a utilização de um agente entomopatogênico em um programa de controle microbiano, é importante realizar a caracterização de isolados que ocorrem no sistema em que o agente será introduzido. Assim, torna-se claro que os resultados obtidos contribuem para o conhecimento do comportamento de isolados de $B$. bassiana associados a A. diaperinus.

Desta forma, o presente estudo não apenas mostrou o potencial da utilização de $B$. bassiana para o controle do cascudinho, mas também comprovou, pela técnica de RAPD, que existem muitas variações genéticas intraespecíficas neste fungo entomopatogênico, constatando-se relações entre os perfis gerados e o hospedeiro inicial dos isolados.

\section{Agradecimentos}

Ao Conselho Nacional de Desenvolvimento Científico e Tecnológico - CNPq, pela concessão de bolsas de produtividade em pesquisa e iniciação cientifica. Ao professor Dr. Ítalo Delalibera $\mathrm{Jr}$ (ESALQ/USP) pela leitura e sugestões oferecidas ao manuscrito.

\section{Referências}

ALVES, L. F. A.; BRESSAN, D. F.; ALVES, V. S.; NEVES, P. M. O. J.; ALVES, S. B. Ocorrência de Metarhizium anisopliae (Metsch.) Sorok. (Moniliales: Moniliaceae) em adultos de cascudinho (Alphitobius 
diaperinus) (Panzer) (Coleoptera: Tenebrionidae), em aviários comerciais em Cascavel, PR. Neotropical Entomology, Londrina, v. 33, n. 6, p. 793-795, 2004.

ALVES, L. F. A.; GASSEN, M. H.; PINTO, F. G. S.; NEVES, P. M. O. J.; ALVES, S. B. Ocorrência natural de Beauveria bassiana (Bals.) Vuilleman (Moliniales: Moniliaceae) sobre o cascudinho (Alphitobius diaperinus) (Panzer) (Coleoptera: Tenebrionidae), em aviário comercial em Cascavel, PR. Neotropical Entomology, Londrina, v. 34, n. 3, p. 507-510, 2005.

ALVES, S. B.; ALMEIDA, J. E. M.; MOINO JUNIOR, A.; ALVES, L. F. A. Técnicas de laboratório. In: ALVES, S. B. (Ed.). Controle microbiano de insetos. 2. ed. Piracicaba: FEALQ, 1998. cap. 20, p. 637-712.

BERRETTA, M. F.; LECUONA, R. E.; ZANDOMENI, R. O.; GRAU, O. Genotyping isolates of the entomopathogenic fungus Beauveria bassiana by RAPD with fluorescent labels. Journal of Invertebrate Pathology, San Diego, v. 71, n. 2, p. 145-150, 1998.

BIDOCHKA, M. J.; MCDONALD, M. A.; ST. LEGER, R. J.; ROBERTS, D. W. Differentiation of species and strains of entomopathogenic fungi by random amplification of polymorphic DNA (RAPD). Current Genetics, New York, v. 25, n. 2, p. 107-103, 1994.

BRIDGE, P. D.; PRIOR, C.; SAGBOHAN, J.; LOMER, C. J.; CAREY, M.; BUDDIE, A. Molecular characterization of isolates of Metarhizium from locusts and grasshoppers. Biodiversity and Conservation, London, v. 6, n. 2, p. 177-189, 1997.

CASTRILLO, L. A.; BROOKS, W. M. Differentiation of Beauveria Bassiana isolates from the Darkling Beetle, Alphitobius diaperinus, using isozyme and RAPD analyses. Journal of Invertebrate Pathology, San Diego, v. 72, n. 3, p. 190-196, 1998.

CASTRILLO, L. A.; WIEGMANN, B. M.; BROOKS, W. M. Genetic variation in Beauveria bassiana populations associated with the Darkling Beetle, Alphitobius diaperinus. Journal of Invertebrate Pathology, San Diego, v. 73, n. 3, p. 269-275, 1999.

CHERNAKI-LEFFER, A. M. Dinâmica populacional, estimativa da resistência a inseticidas e alternativas de controle para o cascudinho Alphitobius diaperinus (Panzer, 1797) (Coleoptera: Tenebrionidae). 2004. Tese (Doutorado em Zoologia) - Departamento de Zoologia. Universidade Federal do Paraná, Curitiba.

CHERNAKI-LEFFER, A. M.; LAZZARI, F. A.; LAZZARI, S. M. N.; ALMEIDA, L. M. Controle do cascudinho. Avicultura Industrial, São Paulo, v. 92 , n. 1094, p. 22-25, 2001.
CRAWFORD, P. J.; BROOKS, W. M.; ARENDS, J. J. Efficacy of field-isolated strains of Beauveria bassiana (Moniliales: Moniliaceae) as microbial control agents of the Lesser Mealworm (Coleoptera: Tenebrionidae). Journal of Economic Entomology, Lanham, v. 91, n. 6, p. 1295-1301, 1998.

DALZOTO, P. R.; GLIENKE-BLANCO, C.; KAVACORDEIRO, V.; RIBEIRO, J. Z.; KITAJIMA, E. W.; AZEVEDO, J. L. Horizontal transfer and hypovirulence associated with double-stranded RNA in Beauveria bassiana. Mycological Research, Cambridge, v. 110, n. 12, p. 1475-1481, 2006.

DEVI, K. U.; PADMAVATHI, J.; SHARMA, H. C.; SEETHARAMA, N. Laboratory evaluation of the virulence of Beauveria bassiana isolates to the sorghum shoot borer Chilopartellus Swinhoe (Lepidoptera: Pyralidae) and their characterization by RAPD-PCR. World Journal of Microbiology and Biotechnology, Oxford, v. 17, n. 2, p. 131-137, 2001.

DOLCI, P.; GUGLIELMO, F.; SECCHI, F.; OZINO, O. I. Persistence and efficacy of Beauveria brongniartii strains applied as biocontrol agents against Melolontha melolontha in the Valley of Aosta (northwest Italy). Journal of Applied Microbiology, Oxford, v. 100, n. 5, p. 1063-1072, 2006.

FERNANDES, E. K. K.; COSTA, G. L.; MORAES, A. M. L.; ZAHNER, V.; BITTENCOURT, V. R. E. P. Study on morphology, pathogenicity, and genetic variability of Beauveria bassiana isolates obtained from Boophilus microplus tick. Parasitology Research, Berlin, v. 98, n. 4, p. 324-332, 2006.

FUNGARO, M. H. P. Diversity among soil insect isolates of Metarhizium anisopliae detected by RAPD. Letters in Applied Microbiology, Oxford, v. 22, n. 6, p. 389-392, 1996.

GAITAN,A.;VALDERRAMA,A. M.; SALDARRIAGA, G.; VELEZ, P.; BUSTILLO, A. Genetic variability of Beauveria bassiana associated with the Coffee Berry Borer Hypothenemus hampei and other insects. Mycological Research, Cambridge, v. 106, n. 11, p. 1307-1314, 2002.

GEDEN, C. J.; ARENDS, J. J.; RUTZ, D. A.; STEINKRAUS, D. C. Laboratory evaluation of Beauveria bassiana (Moniliales: Moniliaceae) against the Lesser Mealworm, Alphitobius diaperinus (Coleoptera: Tenebrionidae), in poultry litter, soil, and a pupal trap. Biological Control, Orlando, v. 13, n. 2, p. 71-77, 1998.

GINDIN, G.; GLAZER, I.; MISHOUTCHENKO, A.; SAMISH, M. Entomopathogenic fungi as a potential control agent against the lesser mealworm, Alphitobius 
diaperinus in broiler houses. BioControl, Dordrecht, v. 54, n. 4, p. 549-558, 2009.

GLARE, T. R.; INWOOD, A. J. Morphological and genetic characterization of Beauveria ssp. from New Zealand. Mycological Research, Cambridge, v. 102, n. 2, p. 250-256, 1998.

HEGEDUS, D. D.; KHACHATOURIANS, G. G. Identification and differentiation of the entomopathogenic fungus Beauveria bassiana using polymerase chain reaction and single-strand conformation polymorphism analysis. Journal of Invertebrate Pathology, San Diego, v. 67, n. 3, p. 289299, 1996.

HUNST, P. L.; LATTERELL, F. M.; ROSSI, A. E. Variation in double stranded RNA from isolates of Pyricularia oryza. Phytopathology, Saint Paul, v. 76, p. 674-678, 1986.

LUZ, C.; TIGANO, M. S.; SILVA, I. G.; CORDEIRO, C. M. T.; ALJANABI, S. M. Selection of Beauveria bassiana and Metarhizium anisopliae isolates to control Triatoma infestans. Memórias do Instituto Oswaldo Cruz, Rio de Janeiro, v. 93, n. 6, p. 839-846, 1998.

MARTINS, M. K.; FURLANETO, M. C.; SOSAGOMEZ, D. R.; FARIA, M. R.; FUNGARO, M. H. Double-stranded RNA in the entomopathogenic fungus Metarhizium flavoviride. Current Genetics, New York, v. 36, n. 1/2, p. 94-97. 1999.

MAURER, P.; COUTEAUDIER, Y.; GIRARD, P. A.; BRIDGE, P. D.; RIBA, G. Genetic diversity of Beauveria bassiana and relatedness to host insect range. Mycological Research, Cambridge, v. 101, n. 2, p. 159164, 1997.

RAEDER, U.; BRODA, P. Rapid preparation of DNA from filamentous fungi. Letters in Applied Microbiology, Oxford, v. 1, n. 1, p. 17-20, 1985.

ROHDE, C.; ALVES, L. F. A.; BRESSAN, D. F.; NEVES, P. M. O. J.; SILVA, E. R. L.; ALVES, S. B.; ALMEIDA, J. E. M. Seleção de isolados de fungos para o controle do cascudinho Alphitobius diaperinus (Panzer) (Coleoptera:
Tenebrionidae). Neotropical Entomology, Londrina, v. 35, n. 2, p. 231-240, 2006.

SANTORO, P. H.; NEVES, P. M. O. J.; ALEXANDRE, T. M.; SARTORI, D.; ALVES, L. F. A.; FUNGARO, M. H. P. Selection of Beauveria bassiana isolates to control Alphitobius diaperinus. Journal of Invertebrate Pathology, San Diego, v. 97, n. 2, p. 83-90, 2008.

SAS INSTITUTE. SAS/STAT. User's guide. Versão 9.1.3, Cary, NC, USA., 2003.

SNEATH, P. H. A.; SOKAL, R. R. Numerical taxonomy. San Francisco: Freeman, 1973. 573 p.

SOSA-GÓMEZ, D. R.; TIGANO, M. S.; ARANTES, O. M. N. Caracterização de entomopatógenos. In: ALVES, S. B. (Ed.). Controle microbiano de insetos. 2. ed. Piracicaba: FEALQ, 1998. cap. 20, p. 731-764.

STEINKRAUS, D. C.; GEDEN, C. J.; RUTZ, D. A. Susceptibility of lesser mealworm (Coleoptera: Tenebrionidae) to Beauveria bassiana: Effects of host stage, formulation, substrate and host passage. Journal of Medical Entomology, Lanhan, v. 28, n. 3, p. 314-321, 1991.

TIGANO-MILANI, M. S.; GOMES, A. C. M. M.; SOBRAL, B. W. S. Genetic variability among Brazilian isolates of the entomopathogenic fungus Metarhizium anisopliae. Journal of Invertebrate Pathology, San Diego, v. 65, n. 2, p. 206-210, 1995.

URTZ, B. E.; RICE, W. C. RAPD-PCR characterization of the Beauveria bassiana isolates from the Rice Water Weevil Lissorhoptrus oryzophilus. Letters in Applied Microbiology, Oxford, v. 25, n. 6, p. 405-409, 1997.

WELSH, J.; MCCLELLAND, M. Fingerprinting genomes using PCR with arbitrary primers. Nucleic Acids Research, Oxford, v. 18, n. 24, p. 7213-7218, 1990.

WILLIAMS, J. G. K.; KUBELIK, A. R.; LIVAK, K. J.; RAFALSKI, J. A.; TINGEY, S. V. DNA polymorphism amplified by arbitrary primers are useful as genetic markers. Nucleic Acids Research, Oxford, v. 18, n. 22, p. 6531-6535, 1990. 